\title{
Observations on healing process of wall ulcers with concurrent digital dermatitis in 52 cattle: gross and light microscopic pathology
}

\author{
Mohsen Nouri ${ }^{1, *}$, Javad Ashrafi-Helan ${ }^{2}$ \\ ${ }^{1}$ Mehregan Veterinary Group, Tehran, Iran \\ ${ }^{2}$ Department of Pathology, Faculty of Veterinary Medicine, the University of Tabriz, Tabriz, Iran
}

\author{
Email address: \\ mnouri2@yahoo.com(M. Nouri)
}

\section{To cite this article:}

Mohsen Nouri, Javad Ashrafi Helan. Observations on Healing Process of Wall Ulcers with Concurrent Digital Dermatitis in 52 Cattle: Gross and Light Microscopic Pathology. Animal and Veterinary Sciences. Vol. 1, No. 6, 2013 , pp. 60-65. doi: 10.11648/j.avs.20130106.13

\begin{abstract}
This paper describes the healing process of the axial and abaxial wall ulcers in cases of concurrent digital dermatitis by gross, histopathologic and therapeutic implications. Fifty two cases showed wall ulcers (13\%); the prevalence rate of affected cases by abaxial wall ulcer and axial wall ulcer were 3.2 and $9.7 \%$, respectively. The herd had endemic digital dermatitis with prevalence in the adult herd of over $34.2 \%$. All the 'non-healing' claw disorders observed in this study were particularly severe, penetrating the horn and involving the corium. In most of cases the fissure was filled with granulated tissue. In $5(9.6 \%), 6(11.5 \%), 6(11.5 \%)$ and $2(3.8 \%)$ of all cattle the claw lesions did not heal after $2,3,4$ and 6 months, respecitively. In $8(15.3 \%)$ lesions the exposed corium was never covered by new horn during the 8 month. Microscopically, there was extremely proliferative epidermis, 2-3 times as high as in the controls with severe acanthosis and rete ridge formation. Stratum corneum was hyperplastic. The evidences of healing as reduce of inflammatory reactions in dermis and repair of epidermis were observed at least after 4 weeks in early lesions. Atypical digital dermatitis must be considered an emergency.
\end{abstract}

Keywords: Wall Ulcer, Digital Dermatitis, Granulation Tissue, Corium, Histopathology, Treatment

\section{Introduction}

Bovine digital dermatitis (BDD) is an infectious condition primarily affecting the interdigital skin at the base of the claws and has a negative economic impact $[1,2]$. It was first reported in Italy [3] and has since spread to most countries in the world, including Asian countries [4, 5]. In Iran, BDD is the most common skin lesion observed in association with bovine lameness. Recent studies in Iran have identified BDD in $30 \%$ of cows [6, 7]. The clinical and histopathological characteristics of BDD have been previously described [8, 9]. The major aetiological infectious agents in BDD lesions are reported to be spirochaetal bacteria $[9,10]$.

Abaxial wall ulcer (AbWU) and axial wall ulcer (AxWU) sometimes known as non-healing white line lesions are rare conditions in cattle digital lesions $[11,12]$. The early stages of these lesions are similar to vertical fissures and axial wall fissures. The causes of wall ulcers have not been determined, although contributing factors, such as environmental trauma, dehydration, conformation (genetic) factors and trace element deficiencies have been speculated upon [6, 12-14]. The prevalence of WU was $20 \%$ in some herds in Netherlands [15]. Both of them can result in moderate to severe lameness and economic loss in dairy cattle [13]; Deep WU is one of predisposing lesion for septic arthritis $[16,17]$ which can be one of the most common reasons for premature culling [18].

Wall ulcers are very rare conditions in cattle in Iran and in most veterinary literature on bovine lameness the lesions are not mentioned. The treatment and prevention of AbWU diseases in cattle are briefly discussed [14, 15, 19, 20]. This paper describes the healing process of the axial wall ulcer and abaxial wall ulcer in cases of concurrent bovine digital dermatitis by gross, histopathologic and therapeutic implications. 


\section{Materials and Methods}

\subsection{Case Selection and Management}

Between January and July 2010, 52 Holstein cattle having wall ulcers (39 cases with AxWU and 13 cases with AbWU) were treated and the healing process was observed in the course of veterinary practice over a period of 8 months. The practice is located in a commercial dairy farm with 400 milking cattle in Nazarabad in West Tehran. The cattle were attended at the request of a farmer and the details of each cow were recorded on a prepared lameness form at completion of the farm visit. The cattle were from a drylot dairy and fed a total-mixed ration. The diet consisted of alfalfa hay, corn silage and a commercial concentrate. In order to be included in the study the animals had to have no clinical evidence of systemic disease. The range of age of the animals was between 2.5 to 10.5 years. Overcrowding, poor drainage and accumulation of feces and urine on floors and basis of the concrete bunk was obvious in this farm. This farm had at least one cattle's foot trimmed in the past (more than 1 year ago) and foot trimmers are allowed to treat lame cattle.

\subsection{Surgical Procedures}

The animals were examined in a claw trimming box and the affected limbs were raised and the claws were trimmed in accordance with the principle of therapeutic foot care [11]. The lesion were washed and dried. The fissures open to drain the underlying infection and pared of the loose horn edges adjacent to the fissure, using a sharp hoof-knife and the Moto-flex tool with a suitable burr attached. These dorsal defects can hardly be reached during surgical treatment in a common standing hoof trimming crash. Access from the dorsolateral and dorsomedial aspects made it possible to remove all the damaged tissue of AbWU and AxWU, respectively. Necrotic tissue and granulation tissue were thoroughly removed from the entire claw lesion and the margins of the fissures in animals equal with surface of the corium and either a wooden block fixed to the sound claw, and the lesion flushed with $200 \mathrm{ml}$ of $0.9 \%$ isotonic saline solution with diluted $0.5 \%$ povidone-iodine solution using a syringe $50 \mathrm{cc}$ twice a day for three consecutive days. Systemic antibiotics consisted of the intramuscular administration of oxytetracycline hydrochloride LA (2-5 $\mathrm{mg} / \mathrm{kg}$ ) at three- to five-day intervals for four weeks. On the first, third, fifth and seventh days after the surgery, the animals were given $2.2 \mathrm{mg} / \mathrm{kg}$ bodyweight flunixin meglumine (Meganix, Erfan-Darou Co.) as an antiinflammatory. Foot preparation was the same in all cases.

\subsection{Healing of Claw Lesions}

The evaluation of the healing process was based on quality and rate of the new horn formation, recovery from lameness and sensitivity to hoof testers. Clinical examinations were conducted on day $0,10,20,30,60,90,120$,
150 and 180. Lameness and new horn formation was recorded by the same clinician. The injury was then photographed by digital camera (model EOS-350D, Canon, Tokyo, Japan). As a parameter for the healing potential of exposed corium the healing process was judged after treatment and was evaluated by routine histopathological studies.

\subsection{Tissue and Microslide Preparation}

The tissue samples were gathered from the granulation tissue of the affected claw with AxWU and AbWU, giving a total 75 sections originating from 25 feet. Specimen jars filled with neutral buffered $10 \%$ formalin for fixation and shipment of specimens to laboratory. Tissues were processed by standard histologic techniques and stained with hematoxylin and eosin (HE) method. Light microscopy was used to evaluate the healing process of lesions.

\section{Results}

\subsection{Case Selection}

Fifty two cases of 400 milking cow showed wall ulcers (13.0\%); the prevalence rate of affected cases by AbWU and AxWU were 3.2 and $9.7 \%$, respectively. The prevalence rate of claw lesions in the hind limb was higher than fore limb. The herd had endemic DD with prevalence in the adult herd of over $34.2 \%$.

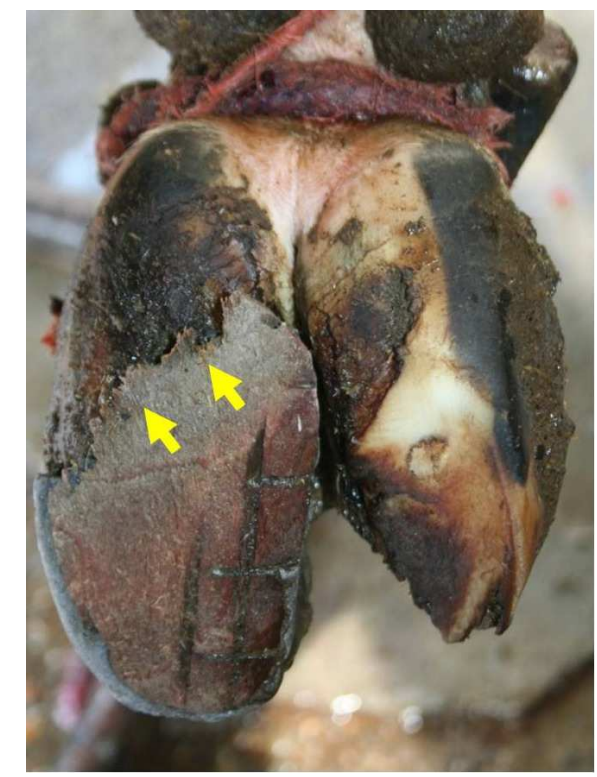

Fig 1. The affected cattle use the caudal aspect of solar surface for weight bearing, the wooden block does not make full contact with the ground and is worn unevenly (yellow arrow).

All the 'non-healing' claw disorders observed in this study were particularly severe, penetrating the horn and involving the corium. The disorders that have been recognised previously in classical form (White line disease) were larger and much more destructive of the surrounding 
tissues than is usually seen. Most of the cases showed abnormal weight bearing and using the caudal aspect of solar surface for weight bearing with the toe raised in standing and walking time and even the solar surface of the sound claw was angled, too. More than seventy one per cent of the claws with AxWU did not have any sign of functional trimming for a long term (more than 1 year) $(71.7 \%)$. Twenty three per cent of the claws with AxWU showed screw claw typically. The wooden block had worn excessively at the heel, so that there was some dorsal rotation of the toe of the sound claw which was uncomfortable for the cattle (Fig. 1). In most of cases the fissure filled with granulation tissue and the lameness did not increase in severity. Fig 2 shows number of cases of AbWU and AxWU recorded during each month of the practice from January to July 2010.

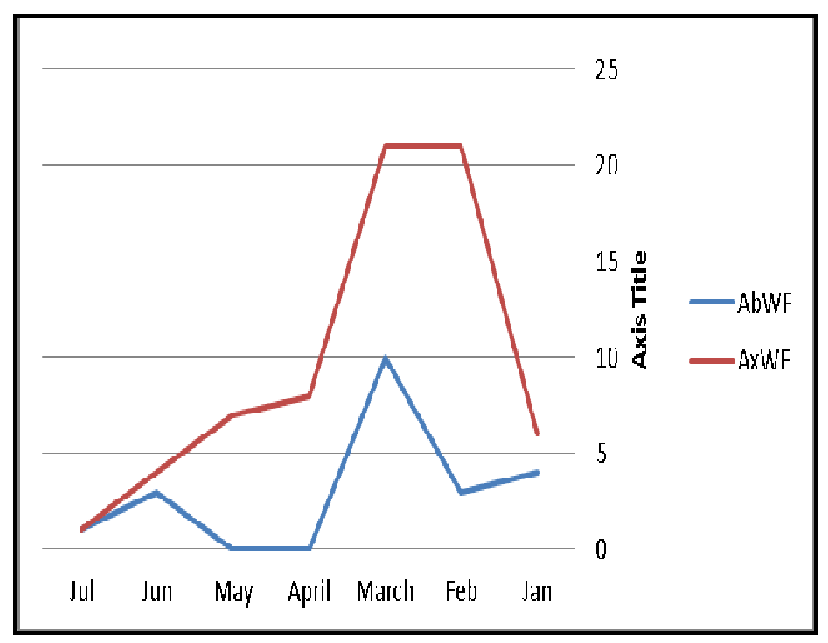

Fig 2. Number of cases of $A b W U$ and AxWU recorded during each month of the practice from January to July 2010 in a commercial dairy farm with 400 milking cattle.

\subsection{Treatment and Outcome}

\subsubsection{Overall Healing}

During the 8-month period $52.0 \%$ of the 52 cattle recovered uneventfully from their claw lesions. In $5(9.6 \%)$, $6(11.5 \%), 6(11.5 \%)$ and $2(3.8 \%)$ of all cattle the claw lesions did not heal after 2, 3, 4 and 6 months. Digits of 8 cows were amputated during the period of evaluation. During the evaluation $25(48.0 \%)$ of the 52 cattle had been treated for 2 or more lesions. Fig 3 shows the steady improvement of the lesion during the first 30 days after treatment.

\subsubsection{Rate of New Horn Formation}

After 30 days $51.9 \%$ and after 60 days $61.5 \%$ of all lesions were completely covered by a solid layer of new horn. In $8(15.3 \%)$ lesions the exposed corium was never covered by new horn during the 8 month. The mean time for the formation of a closed layer of horn was 30 days for lesions with slight corium alterations. Longer-standing lesions indicated severe alterations with involvement of the tip of the claw without formation of horn.

\subsubsection{Short Term Healing}

The evidences of short term healing as reduce of inflammatory reactions in dermis and repair of epidermis were observed at least after 4 weeks. The other cases did not show good progress in healing. The size of the lesions and the locomotion score had significantly decreased, but lesions were not yet covered by new horn.

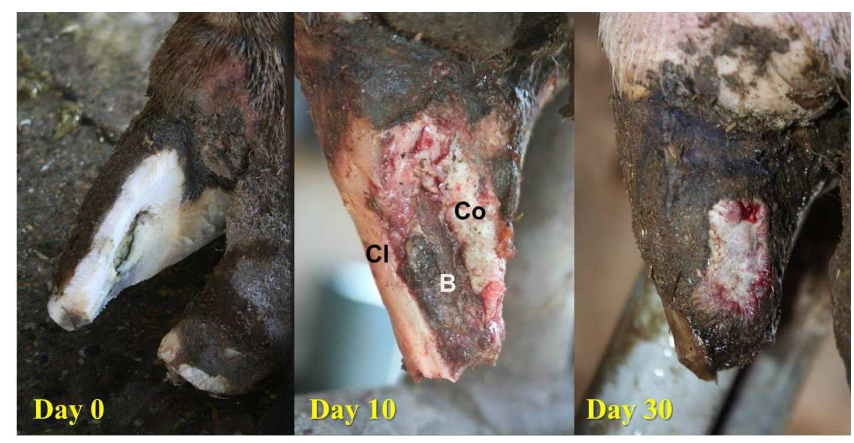

Fig 3. a split aligned along the line of the axial groove of the trimmed claw that is showing the steady improvement of the same lesion during day 0, 10 and 30. (Cl: Claw, B: Bone, Co: Corium).

\subsection{Histopathological Findings}

Microscopically, there was extremely proliferative epidermis, 2-3 times as high as in the controls with severe acanthosis, rete ridge formation and evidences of hydropic change in acanthocytes. Stratum corneum was hyperplastic. Also, mild to massive bacterial infection as microcolonies lied up and under the stratum corneum but sometimes in the stratum granulosum. The stratum corneum were filled with neutrophils, cellular debris and erythrocytes lodged in the orthokeratotic stratum corneum. There was severe hyperemia, slight to severe chronic inflammatory reaction with neutrophilic polymorphonuclear inflammatory infiltrates of the superficial dermis and occasionally deep dermis of the skin and mild infiltration of mononuclear cells such as lymphocytes and plasma cells were also present (Fig 4 and 5).

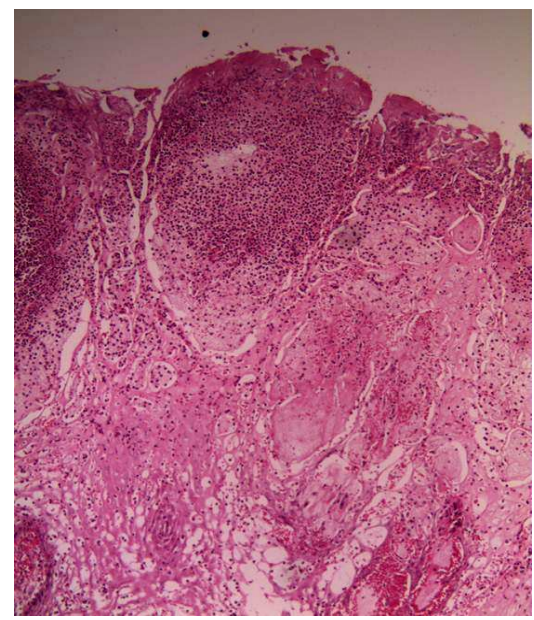

Fig 4. a microscopic view of digital lesion (first week), hyperemia, severe fibrinopurulent exudates and superficial hemorrhage are seen $(H \& E, \times$ 100). 


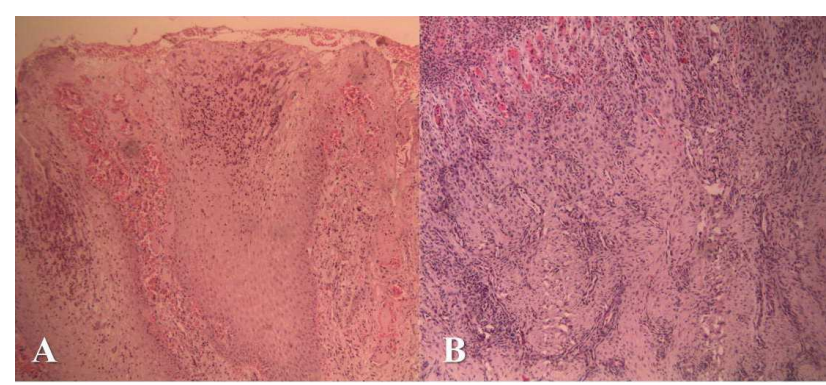

Fig 5. A. Histopathologic view of digital lesion (after 4 weeks), hyperemia, inflammation decreased and evidences of proper healing of epidermis are observed $(H \& E, \times 100)$. B. a microscopic view of digital lesion (after 7 weeks), hyperemia, fibrosis with a lot of collagen synthesis and newly formed blood vessels are noticed $(H \& E, \times 100)$.

\section{Discussion}

In this study, these non-healing disorders were identified as claw lesions that exhibited a topical granular appearance with a typical pungent smell and severely painful when touched, and typically originated from farms where BDD was endemic and not well controlled. The persistence of infection at the exposed corium of the claw is an important reason for a failure of therapy $[13,16,20]$. In fact, a recurrent infection of the granulation tissue inhibits the growth of the horn above the lesion. It is therefore necessary to remove granulation tissue and maintain consistently high local concentrations of antibiotic after the removal of septic material, topically. Also, the margins of the fissures in animals should be equaled with surface of the corium to prevent the anaerobic condition in the area of the undermined horn creates a perfect condition for localization of infectious agents.

Each time the cattle bears weight on the affected claw, the two edges of the crack will be pulling or pushing sensitive lamellae in directions not intended. This will be painful and eventually stimulate the formation of granulation tissue [11, 21]. Van Amstel (2011) found that the formation of exuberant granulation tissue is an important response to infections associated with digital dermatitis [20].

It has been reported that debridement followed by a topical dressing of antibiotic and copper sulphate [19] plus parenteral long-acting cephalosporin treatment [13] yielded promising results in early lesions. Others described the successful use of salicylic acid [14] or dexamethasone and oxytetracycline powder [20].

The application of wooden block often provides a sufficient difference in height between the claws to relieve weight bearing and promote recovery of claw lesions [22]. On the other hand, it should be constructed in suitable size to reduce potential hazard. The most common problem encountered is that with AxWU especially, the wooden block cannot be placed sufficiently far back on the sole to give full support to the heel. Because of painful condition at exposed granulation of the toe region, the affected cattle can't weight bearing on the toe and most of them use the caudal half part of the solar surface for weight bearing. This can result in a caudal rotation of the wooden block, lifting of the toe, stretching of the flexor tendons and impairment of locomotion. The consequent upward deviation of the toe leads to extensive overgrowth at toe, because the sole of the claw does not make full contact with the ground and is worn unevenly. Most of the affected claws therefore required periodic corrective claw trimming. Flaky or chalky white powdery sole, hemorrhage of the heel and heel ulcer are the disadvantages of the application of small wooden block on the heel. Thus, these cows may have to be supplied with new blocks every two months to heal.

Samples of diseased tissue subjected to PCR assays were strongly associated with BDD treponemes [13, 14, 20]. In the present study, these disorders often require individually adapted and complex local and systemic therapy. Although not specifically tested, it appears from the results of these studies and personal experience that a wide variety of antimicrobial drugs, such as penicillin, ampicillin, sulfonamides, tetracyclines or cephalosporins are effective.

Antibiotics alone, even protracted courses of treatment for two to three weeks, were not sufficient in these cases. The large open wound left exposed to faeces and general environmental contamination retard healing significantly [23]. On the other hand, longer term exposure to slurry (up to $14 \mathrm{~d}$ ) can increase the size and depth of pre-existing fissures in poor quality hooves [24], and this could lead to deeper invasion of harmful environmental and infectious agents $[25,26]$. Use of repeated flushing of the wound during the entire healing process seems to be essential so as to avoid contamination and re-infection of the wound by bacteria and most notably BDD-associated treponemes in endemically infected herds and achieve complete healing. Although this treatment may increase the rate of healing, it is labour-intensive in the current series. If povidone-iodine is used, we recommend flushing the lesion with isotonic saline before antibiotics are applied since interactions between iodine and antibiotics could occur. This measure affects a washing as well as a disinfectant action. As skin lesions usually regress spontaneously when the environment is cleaned up, proper management of manure and slurry removal as well as proper housing facilities is important [22].

Trace elements are essential for the growth of goodquality claw horn. Daily supplementation of the diet with biotin in dairy cattle has been shown to increase the plasma concentrations of biotin and reduce lameness problems [14, 27-29]. This is not to suggest that biotin is a cure for wall ulcers, but rather that it is an agent to reinforce the effect of correcting errors in management [30]. In the course of study, the role of trace elements was investigated; Reports from veterinarians and suppliers of supplements indicate that the major criterion used by dairy producer to select a product was its low price.

To suppress the infection pressure of BDD lesions, routine claw trimming and topical individual treatment 
might be advised to enhance the benefit of intervention strategies, such as topical group treatment. In cases topical spray in milking parlor, cows with BDD lesion on the exposed corium will not respond to treatment, compared with cows with lesions on the pastern and remains as a source of lesional material at herd that the disease can be transmitted from animal to animal, permanently. Hernandez and Shearer (2000) indicated that anatomic location of BDD lesions can affect the efficacy of topical spray treatment in cows [31].

Atypical DD must be considered an emergency. Longerstanding lesions lead to involvement of the tip of the claw. More invasive surgical techniques are required in such cases. The invasiveness of the treatment method selected depends on the type of lesion, the extent of involvement of corium, the duration of BDD infection and the practicality of the operation. In acute and subacute cases (two week or less after the onset of lameness), conservative treatment, including topical administration of antibiotics and lesion flushing may be successful. In chronic cases (more than two week after the onset of lameness) with amputation of the affected digit has been recommended. This study recommends that owners of dairy farm should try to control digital dermatitis with preventative herd strategies.

\section{Acknowledgements}

The authors would like to thank Dr. Javad Esmaeili, DVM, private veterinary practitioner for supporting this work and Mr. Mohamad Taghi MirEskandari for histologic assistance. The cooperation of the dairy farmer and claw trimmers in this study was greatly appreciated.

\section{References}

[1] Bicalho RC, Warnick LD, Guard CL. Strategies to analyze milk losses caused by diseases with potential incidence throughout the lactation: a lameness example. J Dairy Sci. 2008; 91: 2653-2661.

[2] Bruijnis MRN, Hogeveen H, Stassen EN. Assessing economic consequences of foot disorders in dairy cattle using a dynamic stochastic simulation model. J Dairy Sci. 2010; 93: 2419-2432.

[3] Cheli R, Mortellaro CM. La dermatite digitale del bovine. Proceeding of the $8^{\text {th }}$ International Meeting on Diseases of Cattle, Milan, Italy, 1974; 208-213.

[4] Nowrouzian I. Digital Dermatitis: an unrecognized epidemic in dairies in Iran, Proceeding of the British Cattle Veterinary Association, Leahurst, Cheshire, 1990; 84-95.

[5] Kimura Y, Mashiro N, Matsumoto N. Verrucose dermatitis and digital papillomatosis in dairy cows. J Vet Med Japan. 1993; 46: 899-906.

[6] Nouri M, Ashrafi-Helan J. Complicated vertical fissures with digital dermatitis in Nazarabad dairy cattle: clinical and gross pathologic findings. Vet Res Forum. 2012; 3(4): 291295.
[7] Zibaee F, Nowrouzian I, Bahonar A. Evidence-based appraisal of water hose as a screening test for detection of papillomatous digital dermatitis in dairy cows: a study on farm level. Proceeding of the $1^{\text {st }}$ Symposium on Lameness in Ruminants, Shiraz, Iran, pp. 2009; 54.

[8] Read DH, Walker RL. Papillomatous digital dermatitis (footwarts) in California dairy cattle: clinical and gross pathologic findings. J Vet Diagn Invest. 1998; 10:67-76.

[9] Döpfer D, ter Huurne AAHM, Cornelisse JL, van Asten AJAM, Koopmans A, Meijer FA, Schukken YH, Szakall I, Klee W, Bosma RB. Histological and bacteriological evaluation of digital dermatitis in cattle, with special reference to spirochaetes and Campylobacter faecalis. Vet Rec. 1997; 140: 620-623.

[10] Yano T, Moe KK, Yamazaki K, Ooka T, Hayashi T, Misawa $\mathrm{N}$. Identification of candidate pathogens of papillomatous digital dermatitis in dairy cattle from quantitative $16 \mathrm{~S}$ rRNA clonal analysis. Vet Microbiol. 2010; 143: 352-362.

[11] Vermunt JJ. Description and treatment of non-infectious claw disease in cattle, Proceeding of the $1^{\text {st }}$ International Symposium of Veterinary Surgery, 10-13 May, Shahrekord, Iran. pp. 2005; 7-26.

[12] Greenough PR. Bovine laminitis and lameness, $1^{\text {st }}$ edn. Saunders Elsevier. 2007.

[13] Evans NJ, Blowey RW, Timofte D, Isherwood DR, Brown JM, Murray R, Paton RJ, Carter SD. Association between bovine digital dermatitis treponemes and a range of 'nonhealing' bovine hoof disorders. Vet Rec. 2011; 168: 214-7.

[14] Holzhauer M, Pijl R. Non-healing white line lesion, advanced experience. Proceeding of the $16^{\text {th }}$ International Symposium on Lameness in Ruminants, New Zealand. 2011; 149.

[15] Holzhauer M, Vos J. Non-healing white line disorders, a new clinical presentation, Proceeding of the $15^{\text {th }}$ International Symposium on lameness in ruminants, Kuopio, Finland, 2008; 206.

[16] Blowey RW. Non-healing hoof lesions in dairy cows. Vet Rec. 2011; 169: 534.

[17] Blowey RW, Chesterton N. Non-healing hoof lesions in dairy cows in Chile. Vet. Rec. 2012; 170: 187-8.

[18] Nouri M, Nowrouzian I, Vajhi A, Marjanmehr SH, Faskhoudi D. Morphometric radiographic findings of the digital region in culling lame cows. Asian J Anim Sci. 2011; 5(4):256-267.

[19] Cook N, Burgi K. "Hairy Attack": A new lesion affecting the corium of the white line - A case report. Proceeding of the $15^{\text {th }}$ Symposium on Lameness in Ruminants, Kuopio, Finland, 2008; 214-5.

[20] van Amstel SR. Treatment approach and histopathology of atypical digital dermatitis lesions. Proceeding of the $16^{\text {th }}$ International Symposium on Lameness in Ruminants, New Zealand, 2011; 26.

[21] Blowy RW. Diseases of the bovine digit, Part 1: Description of common lesions. In Pract. 1992; 14: 85-90.

[22] van Amstel SR and Shearer J. Manual for treatment and control of lameness in cattle, $1^{\text {st }}$ edn. Blackwell publishing. 2006; 73, 165-167, 191-200. 
[23] Blowy R. A simple treatment for heel abscesses and deeper foot infections in cattle. Vet Rec. 1990; 24: 515- 517.

[24] Kempson SA, Langridge A, Jones JA. Slurry, formalin and copper sulphate: the effect on the claw horn. In: Lischer C, Ossent P. (Eds.), Proceedings of the $10^{\text {th }}$ International Symposium on Lameness in Ruminants, Casino Lucerne, Switzerland, 1998; 216-217.

[25] Nuss K, Kostlin RG, Bohmer H, Weaver M. Zur bedeutung der ungulo-coriitis septica (traumatica)- UCS (T)- an der klauenspitze (Sohlenspitzengeschwur) des rindes. Tierarztliche praxis 1990; 18: 567-75.

[26] Gregory N, Craggs L, Hobson N, Krogh C. Softening of cattle hoof soles and swelling of heel horn by environmental agents. Food Chem Toxicol. 2006; 44: 1223-1227.

[27] Distl O, Schmid D. Einfluss einer zufuthering von biotin auf die klauenform, Harte und Gesundheit bei milchkuken. Tierarztlich Umschau. 1992; 49:581-588.
[28] Midla LT, Hoblet KH, Weiss WP, Moeschberger ML. Supplemental dietary biotin for prevention of lesions associated with aseptic subclinical laminitis (pododermatitis aseptica diffusa) in primiparous cows. Am J Vet Res. 1998; 59:733-738.

[29] Campbell JR, Greenough PR, Petrie L. The effects of dietary biotin supplementation on vertical fissures of the claw wall in beef cattle. Can Vet J. 2000; 41:690-694.

[30] Greenough PR. Sand cracks, horizental fissures, and other conditions affecting the wall of the bovine claw. Vet Clin $\mathrm{N}$ Ame- Food Anim. 2001; 17 (1):93-110.

[31] Hernandez J, Shearer JK. Efficacy of oxytetracycline for treatment of papillomatous digital dermatitis lesions on various anatomic locations in dairy cows. J Am Vet Med Assoc 2000; 216(8):1288-1290. 